\title{
Possibilities of Using Plastics in the Design of Water Heater Tank
}

\author{
Natália Jasminská*, Tomáš Brestovič \\ Department of Power engineering, Faculty of Mechanical engineering of Technical University of Košice
}

\section{BIOGRAPHICAL NOTES}

Natália Jasminská, Ing. PhD. - a graduate of Thermal energetics at the Faculty of Metallurgy of the Technical University in Košice (2007). Currently she works at the Department of Power Engineering at the Faculty of Mechanical Engineering of TU Košice as a lecturer. During her PhD studies at the Faculty of Mechanical Engineering she took part in solving research tasks and grant projects where she currently works as a co-solver. Within solving research projects she is the author of more than 70 original publications in national and international magazines and text books.

Tomáš Brestovič, doc. Ing. PhD. he is a graduate of Faculty of Mechanical Engineering, Technical University in Kosice (TUKE). Currently works as a specialized assistant at Department of Power Engineering. He actively participates in research of heat transfer, fluid flow, new technologies in area of renewable energy resources and mathematical modelling of energy processes.

\section{KEY WORDS}

Pressure tank, water heater, plastic, numerical simulation, strength calculation.

\section{ABSTRACT}

This paper deals with the design of a pressure tank for a water heater. Today, new materials and technologies come to the fore at which especially the price for product is of significance. Within Europe, only steel pressure water heaters are produced in series. The design considers the use of an alternative material, namely the plastic. By design optimization, it would be possible to minimize costs for production, as the plastic is a good insulating material, and it is not needed to spend financial means for enamelling, and this material does not require cathodic protection. There are plastics on the market that meet requirements for resistance, they are suitable for use with water at a high temperature and they have a relatively high strength of material. One of such materials is Noryl GFN1630V that contains $30 \%$ of glass fibres and it was selected as an optimal material for strength calculations. Suitable water heater tanks were designed on the basis of the strength calculations.

\section{Introduction}

Today, there is a quick-growing trend in production of new products, and the Slovak companies do not want to lag behind and they try to bring new, more thrifty and economical products to the market. A Slovak company with a long tradition began to be interested in production of a plastic pressure water heater.

The pressure tanks are designed according to the well-tried rules that are the subject of certain set of binding regulations or standards in advanced industrialized states. Such regulations are created during a long period of time and they always reflect the level of knowledge in given time. In spite of the fact, that they are periodically revised 
and completed (after 3-5 years), they cannot contain up-to-date scientific findings. They are sources for solution of more or less standard designing and constructional cases [10].

Plastic has a great positive feature for production of a water heater tank, namely corrosion resistance and, in general, stability of this material to chemical attack. In comparison with metal, plastic has good insulator properties. A big disadvantage of plastics is their non-linear characteristic (in comparison with steel of which characteristic is linear) where plastics experience even half decline of strength properties at the temperature increase [2], [3], [5]. Plastics for the water heater tank should be safe for health. They must be suitable for using with drinking water (according to KTW - Kunststoffe und Trinkwasser). However, not every plastic is specified with characteristic of suitability for the use with drinking water. We put forward plastic as an optimal material for the design of the pressure tank that is approved for the use with foods. If the given material is selected as the most suitable one, it would be necessary to approve it for the use with drinking water according to KTW

During material selection, the highest temperature was taken into consideration which the given plastic withstands, and the tensile strength value of given material at the mentioned temperature [7], [8]. Two plastics from the company Sabic (NoryIGFN3V, Noryl GFN1630V) and one plastic from the American company Ensigner (Tecaform FG Blue) were selected from materials that are available on the market.

\section{Setting Parameters Needed for a Water Heater Pressure Tank}

The values of basic parameters of the tank such as jacket diameter, ellipse height of elliptic bottom, inner radius of inlet and outlet tube, mutual distance and position of tubes at the elliptic bottom are designed in the same way like in the case of water heater tanks that are produced from steel today. The pressure tank from proposed alternative material is an interesting choice, especially, in economic terms, as saving of financial means could occur during production of the plastic water heater.

\subsection{Calculation of jacket thickness of the pressure tank}

On the basis of the primary basic calculation of jacket thickness, the tank was classified as a thinwalled or a thick-walled one. The calculation was made for a 30 I tank of the water heater.

Laplace's equation applies to the cylindrical part of the tank

$$
\frac{\sigma_{m}}{\rho_{m}}+\frac{\sigma_{t}}{\rho_{t}}=\frac{\mathrm{p}}{\mathrm{h}}
$$

Radii of curvature are $\rho t=r, \rho m=\infty$ [6]. After substitution in the equation (1), we receive

$$
\sigma_{t}=\frac{p \cdot r}{h}
$$

For meridional stress, we receive

$$
\sigma_{m}=\frac{p \cdot r}{2 h}
$$

Considering the thin-wall tanks, there is a plane state of stress in the tank wall. Using the strength condition according to the $\mathrm{HMH}$ theory, it is possible to design a minimum thickness of tank jacket material:

$$
\sqrt{\sigma_{t}^{2}+\sigma_{m}^{2}-2 \sigma_{t} \sigma_{m}} \leq \sigma_{D O V}
$$

By joining relations (2) and (4), we receive:

$$
\sqrt{\frac{p^{2} r^{2}}{h^{2}}+\frac{p^{2} r^{2}}{4 h^{2}}-\frac{p^{2} r^{2}}{h^{2}}} \leq \sigma_{D O V}
$$

By modifying the relation (5), we receive the minimum thickness of the jacket:

$$
\frac{p \cdot r}{2 \sigma_{D O V}} \leq h
$$

By substituting known values in the formula (6), it is true that $h \geq 0.61 \mathrm{~mm}$. After substitution of safety coefficient $\eta b=1,6$; it is then true for jacket thickness that $h \geq 0.98 \mathrm{~mm}$.

Designed boiler made of material Noryl GFN1630V will be solved with regard to very low ratio of tank thickness to its diameter (lower than 0.1) by method of thin-walled tanks.

\subsection{Setting force applied to the flange}

The total force applied to the flange will be received as a sum of hydrostatic pressure applied to the flange and of force applied to the packing.

Axial force from hydrostatic pressure transmitted on 


\section{the flange}

This force will be calculated according to [9]

$F_{p}=\frac{\pi}{4} \cdot D^{2} \cdot p$

where $D=0.113 \mathrm{~m}$ is the inner diameter of the flange, $p=660 \mathrm{kPa}$ is the calculation pressure.

After substitution in the formula, it is true that

$F_{p}=\frac{\pi}{4} \cdot 0,113^{2} \cdot 0,66 \cdot 10^{6}=6619 \mathrm{~N}$

\section{Force applied to the packing}

The force will be calculated according to [9]

$$
F_{t}=2 \cdot \pi \cdot G \cdot b \cdot m \cdot p
$$

where $G=0.133 \mathrm{~m}$ is the diameter of reaction force in the sealing, $b=0.007969 \mathrm{~m}$ is an effective width, $\mathrm{m}=1.5$ is the coefficient of packing, (1 to 1.5) will be selected for rubber packing.

Effective width of the packing will be calculated as

$b=2,52 \cdot \sqrt{b_{0}}=2,52 \cdot \sqrt{10}=7,969 \mathrm{~mm}$

where $\mathrm{b} 0=10 \mathrm{~mm}$ is the basic width of the packing.

After substitution in the formula, we receive

$F_{t}=2 \cdot \pi \cdot 0,133 \cdot 0,007969 \cdot 1,5 \cdot 660000=$

$=6592,8 \mathrm{~N}$

\section{The total force applied to the flange is}

$F=F_{p}+F_{t}=6619+6592,8=13211,8 N(12)$

The force will be applied to the part of the flange where it will be fixed with screws. It is necessary to resolve this force into given number of screws.

The force applied to one screw will be

\section{a) $F=2202 \mathrm{~N}$ in case of 6 screws.}

\section{b) $F=1651.5 \mathrm{~N}$ in case of 8 screws.}

\section{Geometry Design and Strength Calculations of the Pressure Tank}

This part of the paper specifies the procedure of geometry design of the water heater tank and calculation results in the programme Ansys 12.1. On the basis of calculations, the tank was modified up to the resulting variant that meets the condition of the tensile strength, which is $85 \mathrm{MPa}$ for the tank under given conditions [1], [4].

\subsection{Pressure tank of a $\mathbf{3 0}$ I water heater}

At an early stage, design of the tank of 30 I water heater was realized. The progress was made at several stages which will be described in detail. The first part solved the water heater tank with six screws on the flange in terms of strength. As the given design was not suitable at certain material thickness, the flange with eight screws began to be solved.

\subsubsection{Design of the flange with six screws for the water heater}

At the initial stage of design, a model of the tank of the 30 I water heater was drawn, without holes for carriage screws yet, and the force was set for the whole lower part of the flange. At the beginning, the material was $6 \mathrm{~mm}$ thick. Following figure shows results of the strength calculation of the initial design.

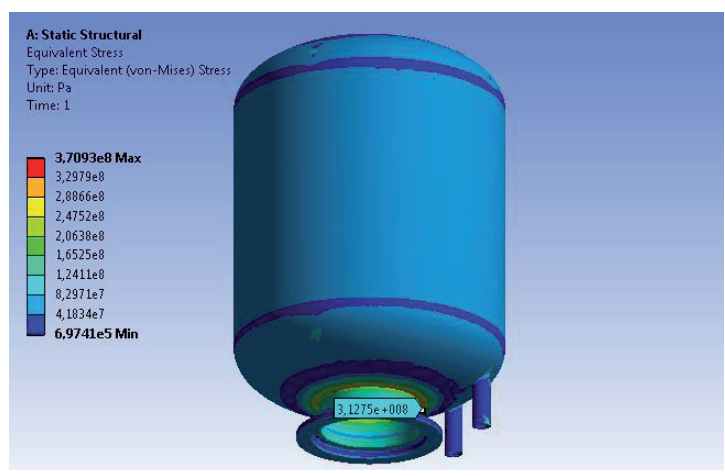

Fig. 1: Input strength calculation of 30 I tank without ribs.

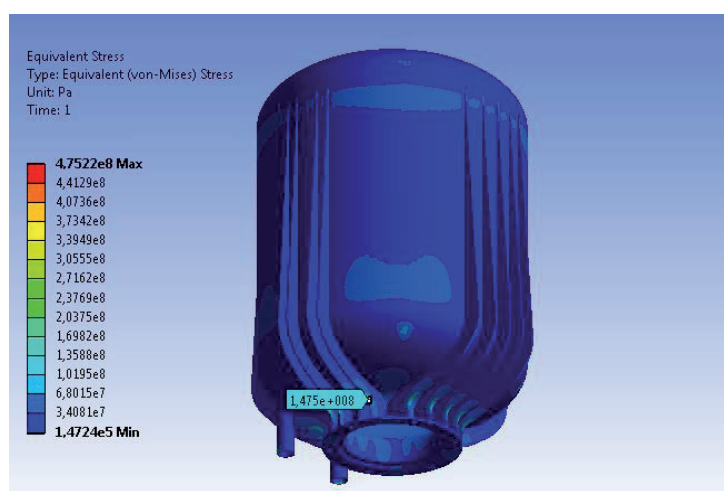

Fig. 2: Input strength calculation of 30 I tank with ribs.

As we can see in Figure 1, the highest force stresses occurred on the neck of the tank and un- 
der the flange. In terms of strength, they highly exceed the tensile strength of given material under given conditions. As the thickness of material will not be higher, ribs were placed in place under the flange, on the neck and along the whole jacket of the tank. Figure 2 shows the strength calculation of this tank variant with the wall thickness

$3.5 \mathrm{~mm}$.

The highest stress that is shown in Figure 2 was observed only on the tube in one point, which is caused by insufficiently dense netting on a relatively deep curvature of geometry. The rib shows the stress $147 \mathrm{MPa}$. Such stresses that exceed the breaking strength are not only in the upper parts of ribs, but also under the flange. As we can see on ribs, high stresses do not occur in their whole part, but they are concentrated in their lower part. At the next stage, the ribs will be shortened, which will result in material saving (Figure 3).

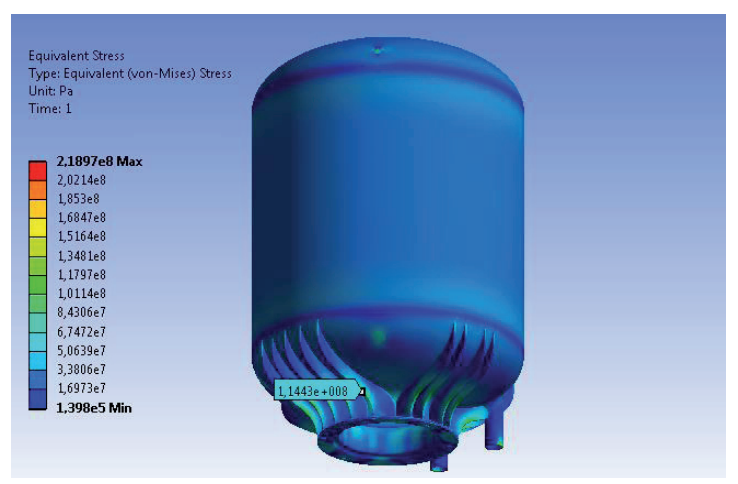

Fig. 3: Strength calculation of 30 I tank with shorter ribs.

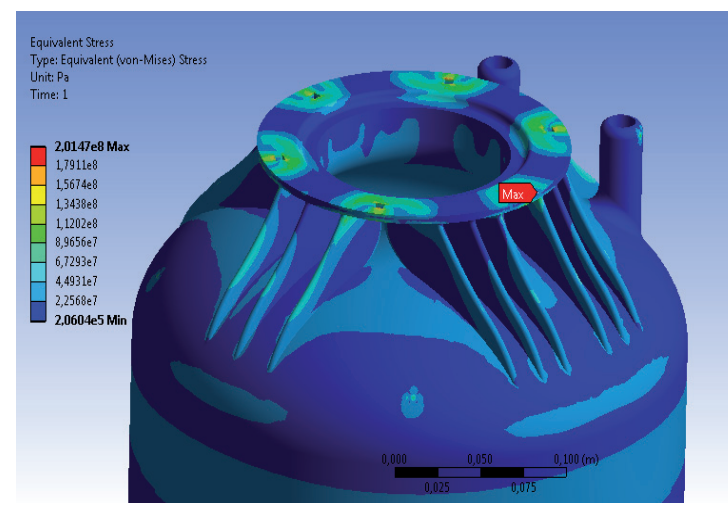

Fig. 4: Strength calculation of 30 I tank with an optimum length of ribs.

As we can see in Figure 3, the maximum stress on ribs is lower than the stress on ribs in Figure 2.
Its more even distribution along the whole ribs occurred.

At the next stage, the ribs will be more shortened, and the holes corresponding with the size of carriage screws M5 will be created on the part of the tank where the flange will be fixed. The force will be set for the whole part of the flange, but in places where the screws will be placed. Figure 4 shows the result of the strength calculation for this tank variant with thickness $3.5 \mathrm{~mm}$.

High force stresses occur in places of screw fixing also at higher thickness of material. These stresses will be eliminated by design of higher number of screws fixed on the flange.

\subsubsection{Design of the flange with eight screws for the water heater}

The first simulation that was performed for the water heater tank with eight screws on the flange was with $3.5 \mathrm{~mm}$ thick material and the holes were for carriage screws with the size M5. The material thickness was the same on the whole part of the flange. The following figure (Figure 6) shows the results of the strength calculation of this variant. Maximum stress that occurred during simulation was in the part of tubes, which is not considered as important for this calculation. It is important to focus on the stress raisers which are in the area of screws and under the flange. There are also stresses in these parts that exceed the breaking strength of given material. These force stresses will be decreased by increasing the material thickness and by changing the size of screws in the next part of the design. Instead of screws M5, bigger screws will be placed there of which head radius will be bigger and, therefore, the force will be resolved into larger area. Then, a series of simulations was performed. First, the thickness of the tank remained, but the size of screws was increased to M8, however, stresses exceeding breaking strength also occurred in this variant. Then, the material thickness was increased to $4.5 \mathrm{~mm}$ only in place of fixing the flange. High stresses still occurred in place of fixing the screws. Then, the thickness of the tank material was increased to $4.5 \mathrm{~mm}$ and to $5.5 \mathrm{~mm}$ in lower part where the flange will be fixed. The result of force stresses met the strength conditions of given material in this strength calculation. Figure 7 shows the result of solution in the programme.

As there was an effort to save material at the next stage, further designs were realized. The mate- 


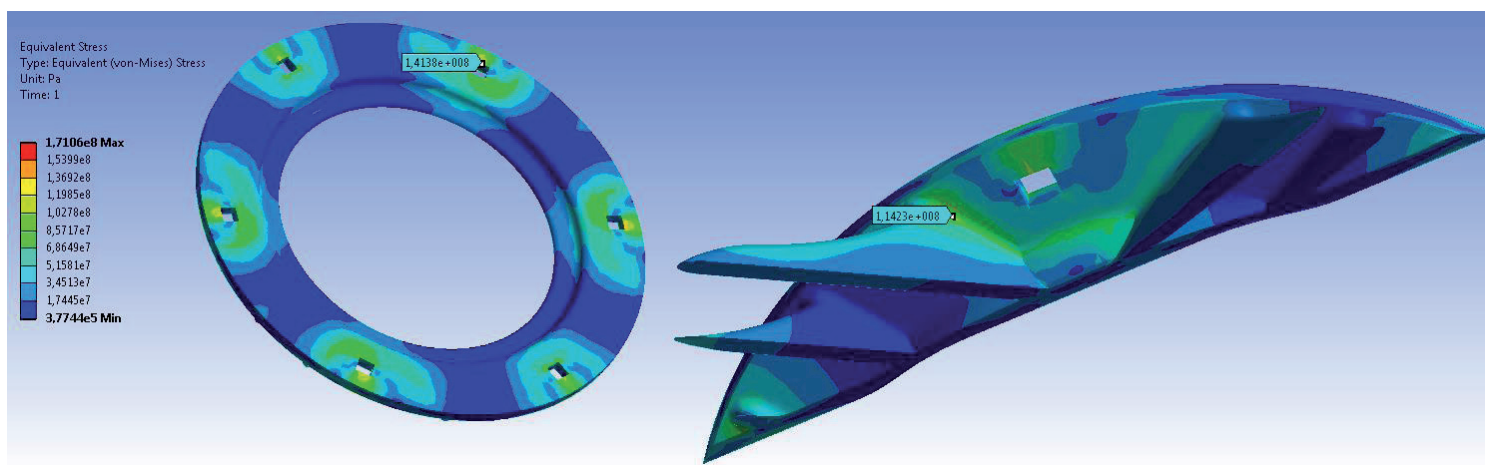

Fig. 5: Strength calculation of 30 I tank with 6 screws

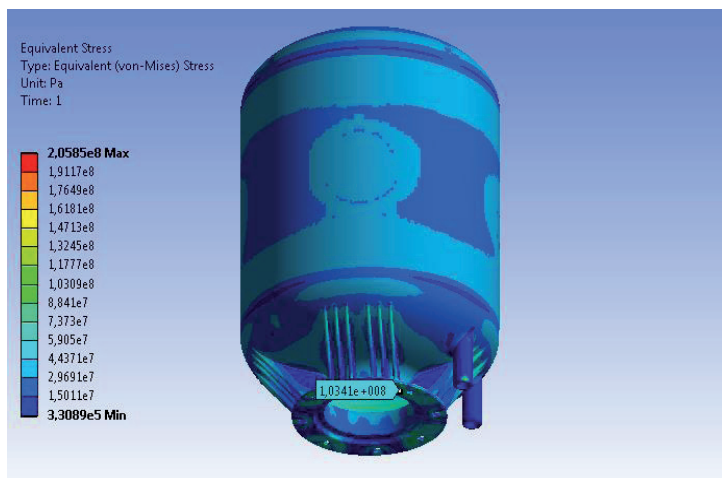

Fig. 6: Strength calculation of 30 I tank with 8 screws and thickness $3.5 \mathrm{~mm}$.

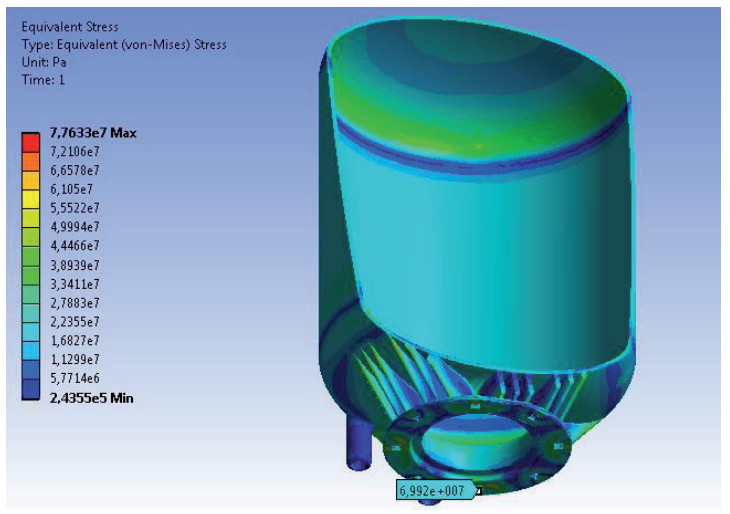

Fig. 7: Strength calculation of 30 I tank with screws and thickness $4.5 \mathrm{~mm}$.

rial thickness of the whole tank was gradually decreased by $0.1 \mathrm{~mm}$. The last variant that meet the strength condition had the material thickness of the tank $4.3 \mathrm{~mm}$ and thickness of the part where the flange will be fixed was $5.3 \mathrm{~mm}$.

Figure 8 shows results of strength calculation of this variant.

The highest stress that was calculated by the pro-

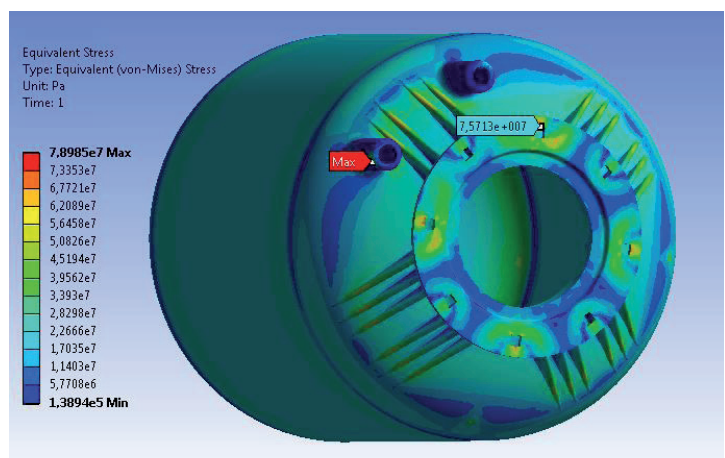

Fig. 8: Strength calculation of 30 I tank with 8 screws and 22 ribs.

gramme was on the tube, which is not considered as important. Maximum stresses ca. $75 \mathrm{MPa}$ were calculated in places around screws, these force stresses were lower under the flange. This variant of solution complies with the strength condition and has been the most suitable variant so far.

As on the side where tubes are placed there are only four ribs, two ribs on the side opposite the tubes were removed at the next stage. The results of the strength calculation were satisfactory after calculating this variant in the programme Ansys. Figure 9 shows a more detailed view of strength calculation of lower part of the tank, of places where the highest force stresses occur. The highest stress was determined on the tube again. The parts where the flange will be fixed have the maximum stress ca. $76 \mathrm{MPa}$. This variant is another one that meets the strength conditions.

The objective of the design was to save as much material as possible and, therefore, we removed two ribs on the other two sides. There were now four ribs under the flange on each side of the tank. The strength calculation should confirm or dis- 


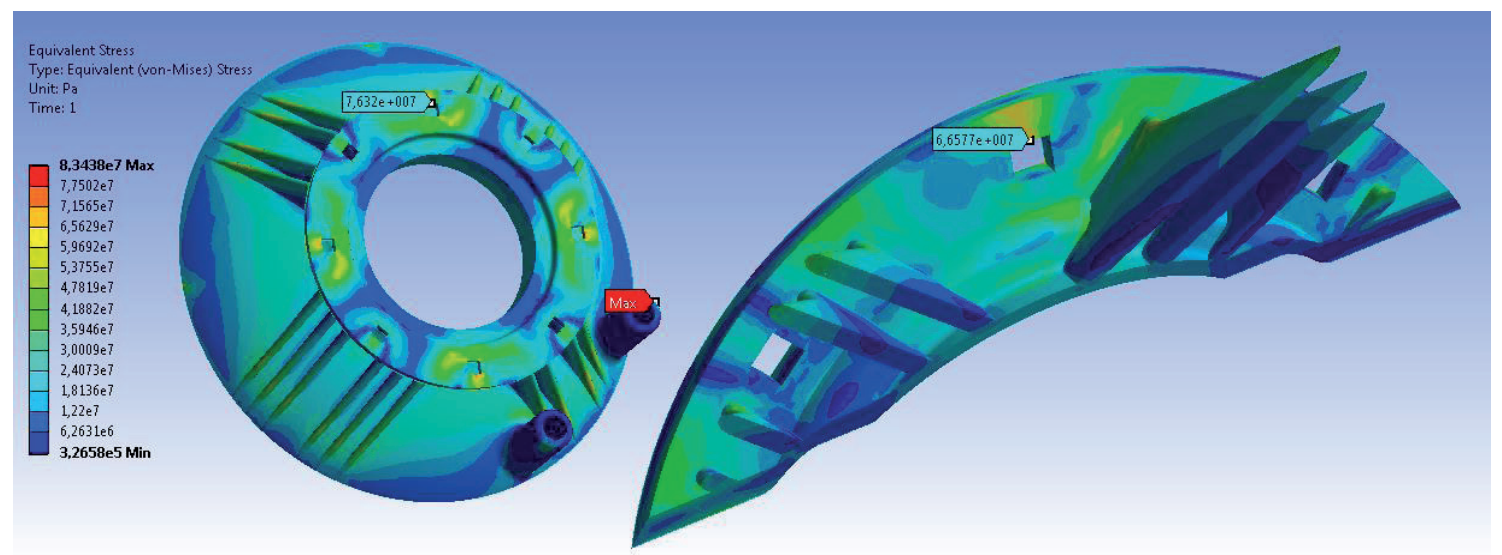

Fig. 9: Strength calculation of 301 tank with 8 screws and 20 ribs.

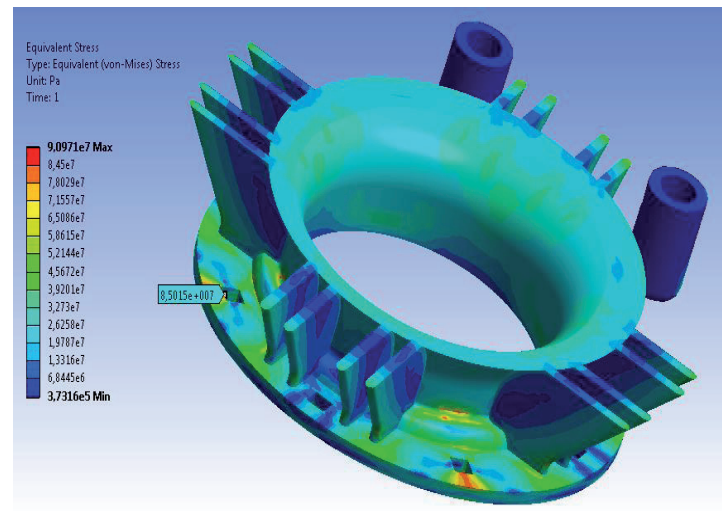

Fig. 10: Strength calculation of 30 I tank with 8 screws and 16 ribs.

prove the fact that four ribs are sufficient on each side of the tank, as this number is sufficient on two sides. The assumption of a sufficient number of 16 ribs was wrong. Fig. 10 shows the result of the strength calculation.

The maximum force strength exceeding the breaking strength of given material occurred in places were screws will be fixed, namely near those ribs that were removed. On the basis of the strength calculation, it can be stated that removed four ribs will be needed in the design of the tank with the jacket thickness $4.3 \mathrm{~mm}$.

Another attempt to save material was reducing thickness of tank material. Figure 11 shows the result of the strength calculation where the thickness of the tank material is $4.2 \mathrm{~mm}$ and in places of fixing the flange $5.2 \mathrm{~mm}$, however, it does not meet the strength conditions. As we can see in the figure, the highest stress is exceeding the breaking strength of given material. The values of the force

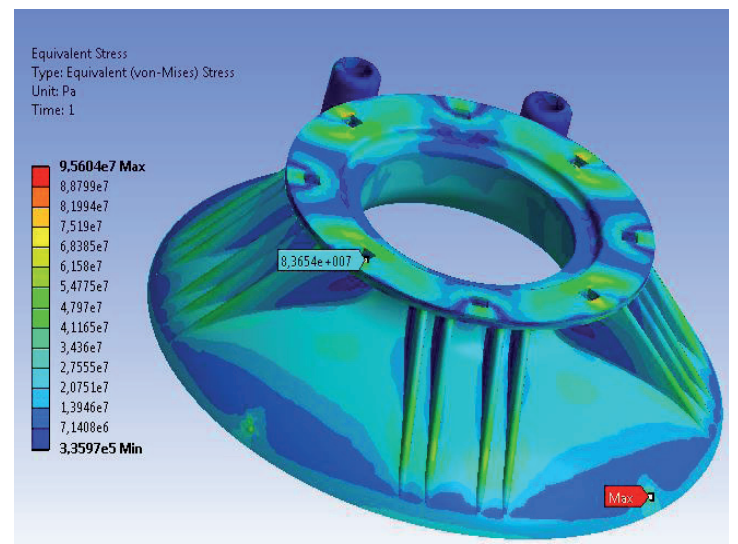

Fig. 11: Strength calculation of 30 I tank with 8 screws and the thickness $4.2 \mathrm{~mm}$.

stress are approaching the value of the breaking strength of given material in places of fixing screws. Therefore, this variant is not considered as suitable for given tank design.

\section{Discussion}

This part of the paper summarises the design results and selection of an optimal solution. First, it has to be noted that these designs were made for material Noryl GFN1630V. In October 2012, the company Sabic presented a new plastic Noryl FE1630PW on the market that will have to better strength properties than Noryl GFN1630V. During design elaboration and strength calculations, the basic material characteristics had not been published yet.

Today, the company has published the values of basic parameters of this plastic, however, it is not sufficient for the strength calculation where it is necessary to know the tensile strength at given tempera- 
ture.

It has to be noted that it will be possible to minimize the thickness of the water heater tank during increase of breaking strength, which will result in material saving.

It was found out during strength calculations of 30 I tank of the water heater that the tank with six screws on the flange will be unsuitable for these designs, it would be necessary to increase the material thickness, as, in such a case, a heavy force is applied to one screw and material would not withstand such a force in the area of screws. Therefore, the result of designs which meet the strength conditions is the tank that has eight carriage screws on the flange, namely M8 type.

At the beginning of designs, it was found out that if the tank was not be strengthened with ribs in the area of the neck and under the flange, a thicker material would be needed. The tank designs were strengthened with ribs that were placed under the flange, on the lower elliptic area. The longer ribs were not necessary any more, as the highest stresses occurred only in the part of the ribs on the lower elliptic area.

During calculations, the attention was paid to the results of force stresses on the tank in the area of the stress raisers, namely in places where the flange will be fixed with screws, and on the tank neck, under the flange.

A suitable design shall meet the strength condition, which means that the force strength does not exceed the value $85 \mathrm{MPa}$.

In case of a 30 I water heater tank, 2 suitable designs were achieved that were satisfactory in terms of strength at the lowest suitable material thickness. Both designs had the material thickness of the tank $4.3 \mathrm{~mm}$ and the thickness of the place of fixing the flange $5.3 \mathrm{~mm}$ (Figure 8 and 9). These designs differed in the number of ribs. In one design, there were 22 ribs under the flange, in another only 20. Both designs had the maximum pressure stress in the raisers ca. $75 \mathrm{MPa}$. With regard to the selection of a more suitable design, the attention was paid, especially, to the material saving. It is obvious that the design that has two ribs lesser will be more favourable in terms of weight. The design with 22 ribs has the weight $3.434 \mathrm{~kg}$ and the design with 20 ribs $3.411 \mathrm{~kg}$.

The most favourable design of a 30 I water heater tank may be the design that has 20 ribs under the flange, and the Figure 9 shows the result of its strength calculation.

It can be concluded that the plastic tank of water heaters will have a lower elliptic bottom in comparison with heater tanks that are today produced with modified placing of ribs under the flange that reduce the force stress in main raisers, and the wall thickness of tanks is approximately double like at a steel tank.

It will be possible to change the thickness in case of designs from other material, namely Noryl FE1630PW that has the tensile strength by $15 \mathrm{MPa}$ higher at the temperature $23^{\circ} \mathrm{C}$. Like Noryl GFN1630V with which the strength calculations were made.

\section{Conclusion}

Finally, it must be added that, today, when new materials, of which properties are still improved, are introduced on the market, it will be possible to lower gradually the given thickness of the tank. At present, the company Sabic has introduced a new material that is better in terms of strength than material with which designs were made. It is only a matter of time when the material properties will be known and it will be possible to perform calculation for new material and to modify the design of the water heater tank.

\section{Acknowledge}

This paper was written with the financial support of the granting agency VEGA of the Ministry of Education of the Slovak Republic within the project solution No. 1/0686/13 and of the granting agency KEGA of the Ministry of Education of the Slovak Republic within the project solution No. 041TUKE-4/2013.

\section{References}

[1] Bojko, M. et al. 2011. Characteristics of a mathematical model of the spiral heat exchanger using CFD ANSYS Fluent. 30. Setkání kateder mechaniky tekutin a termomechaniky. Liberec. pp. 17-19. ISBN 978-80-7372-747-5.

[2] Čarnogurská, M., Bojko, M. 2005. Impact of steam boiler membrane wall shape on its temperature and tension state. Bydgoszcz - Muszyna, Pol'sko, pp. 13-14, ISBN 83-87982-462.

[3] Dolník, B., Tkáč, J., Kurimský, J. 2008. Možnosti ochrany izolácie elektrických zariadení pred účinkami atmosférickej elektriny. In: Starnutie elektroizolačných systémov. č. 5 (2008), s. 7-10. ISSN 1337-0103.

[4] Horyl et al. 2010. Demonstration of the Matsol Library De- 
veloped for the Efficient Solution of Contact Problems and its Comparison with Ansys. Acta Mechanica Slovaca. Vol. 14, Issue 1, pp. 36-93, ISSN 1335-2393.

[5] Jandačka, J., Kapjor, A., Papučík, Š.,Lenhard, R. 2010. Emission and power parameters of combined heat source on wood biomass combustion, Annals of Warsaw University of Life Sciences - SGGW, No 7, pp .245-249, ISSN 1898-5912.

[6] Jaššo, I., Peciar, M. 2000. Konštrukcia výrobných zariadení. Bratislava: STU, 252 s. ISBN 80-227-1372-4.

[7] Osuský, J., Števo, S. 2011. Hybrid Control of Water Level in Tank System. In: International Review of Automatic Control. Vol. 4, No. 6, pp. 977-984. ISSN 1974-6059.

[8] Sabu, T. 2010. HandbookofEngineering and SpecialtyThermoplastics (Polyethers and polyesters). Hoboken, Villey. Volume 3, 2010. 540 p.

[9] Trebuňa, F., Šimčák, F. 2000. Pružnost', pevnost' a plastickost' v príkladoch. Košice: Emilena, 318 s. ISBN 80-7099-277-9.

[10] Zelený, M. 2009. Technology and High Technology: Support Net and Barriers to Innovation. Acta Mechanica Slovaca. Vol. 13, Issue 1, pp. 8-21, ISSN 1335-2393. 